\title{
Chapter 36 \\ STEAM Platform: Transforming Youth \\ Leadership for a Smart Circular \\ Economy
}

\author{
Lerwen Liu
}

\section{The Problem Stated}

The greatly changing global youth population dynamics, especially in the Asian region, along with a significant rise in skilled youth unemployment, is alarming for global organizations. Youth are expected to play a critical role in the rapid development from a linear to a circular economy with the adoption of next-generation technologies such as advanced robotics, big data analytics, artificial intelligence (AI), nanotechnology, biotechnology, 3D printing, Internet of Things (IoT), etc. The convergence of these technologies is transforming food and agriculture, energy and environment, manufacturing, healthcare, and materials. It is critical to equip the future workforce with the convergence of knowledge and skills through capacitybuilding programs that embrace such a technological revolution including Industry 4.0 (IR 4.0) and the so-called smart circular economy.

In the Asian developing countries, particularly non-English-speaking countries such as Thailand, most youth lack confidence and are poor in communication, especially in English. This, together with other cultural reasons, has resulted in the youth of today lacking motivation and clear goals, and they are poor in planning and in the systematic execution of tasks. This has led to poor performance and levels of accomplishment and has created a vicious cycle of lack of motivation, goals, planning, execution, performance, accomplishment, and confidence.

\section{Liu (ه)}

King Mongkut's University of Technology Thonburi, Bangkok, Thailand e-mail: lerwen67@gmail.com 


\section{Finding Possible Remedies}

To address these challenges, the authors of this article created the Science, Technology, Engineering, Arts, and Mathematics or STEAM Platform at King Mongkut's University of Technology Thonburi (KMUTT) in Bangkok in June 2018, to build youth leadership through promoting excellence in research, innovation, education, and entrepreneurship (RIEE) with a focus on young researchers including undergraduate and graduate students.

The STEAM Platform consists of three pillars: knowledge convergence, skills and mindsets, and entrepreneurship (see Figure 36.1). It focuses on four sectors: food/agriculture, energy, materials, and healthcare. STEAM Platform seeks to empower youth in Asia to become global leaders, equipped with the convergence of science, technology, engineering, arts, and mathematics (STEM) knowledge, life cycle thinking, and strategic communication skills and entrepreneurship practices toward the Sustainable Development Goals (SDGs) 2030 and the Smart Circular Economy transformation. This seeks to create a positive cycle of motivation (excellence), goals (SDGs 2030 and Smart Circular Economy related to their studies and research), planning (scientific and systematic thinking), execution (entrepreneurship practices), performance, accomplishment (excellence), and confidence (strategic communication skills).

The STEAM Platform adopts a unique approach (see Figure 36.1) in transforming students and young researchers and faculties at KMUTT who have represented Thailand's leadership in sustainable development through a Smart Circular Economy at various global forums. These approaches are globalization couples with localization; digital couples with physical; peer-to-peer couples with senior-to-youth;

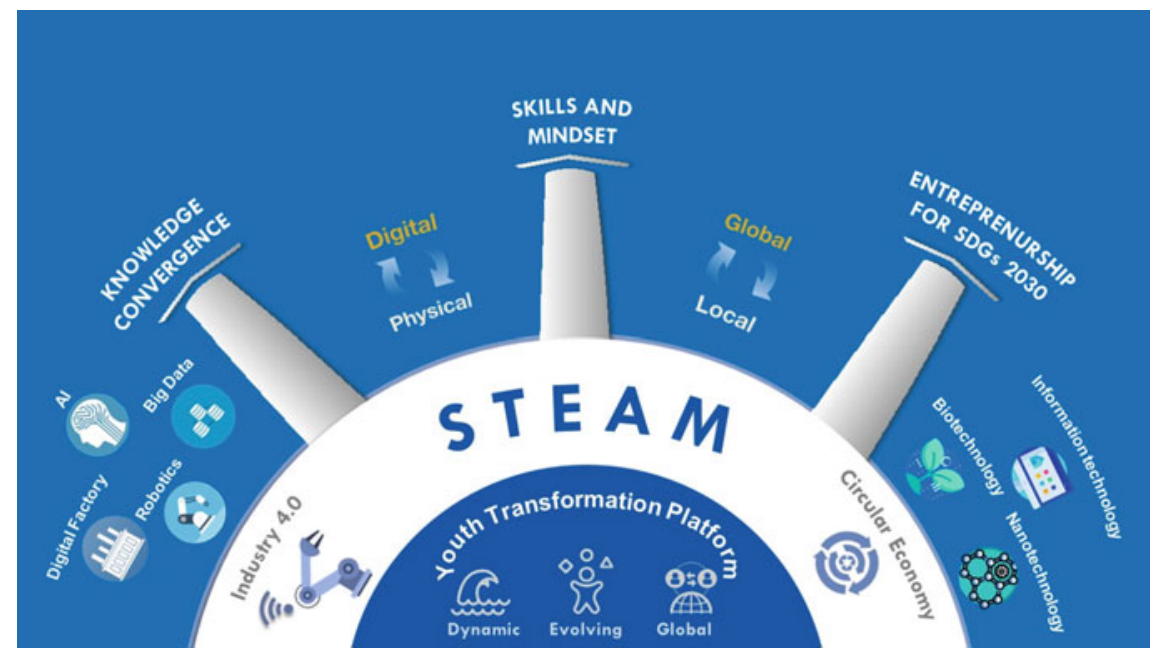

Figure 36.1 STEAM platform framework 
entrepreneurship driven by the convergence of STEAM knowledge and business models (designed according to the sustainability principle, Circular Economy, and SDGs 2030); and skills and mindset developed experientially through STEAM Platform internships.

The Platform provides internships, workshop training, and one-on-one mentorship for youth by forming teams of STEM students/researchers with a diverse technical background and design/communication expertise, guided by technical experts and entrepreneurs. The STEAM interns are provided unique opportunity to showcase their activities in RIEE at global forums, exhibitions, workshops, and seminars where they are able to communicate their ideas and output to their peers overseas as well as to experts from all over the world. The output of the STEAM Platform includes confident and excellent communicators of STEM knowledge and motivated passionate technopreneurs who transform the perception of Asia as global leaders in IR 4.0 and Circular Economy. The STEAM Platform builds partnerships with stakeholders and global players in transforming the world for sustainable development. STEAM integrates AI, biotech, nanotech, and information and communication technology with a sustainable business model (ethics in responsible development) in solving problems and empowering young entrepreneurs in driving the green economic transformation. ${ }^{1}$

\section{How Is This Accomplished?}

The STEAM Platform focuses on the goal of promoting academic excellence and purpose of SDGs 2030 and circular economy transformation through various activities and engagements. Among these are short-term goal-oriented and contemporarily relevant technology innovation contests and showcases at global forums (in Austria; Hong Kong, China; the Republic of Korea; the Philippines; and Singapore within a year) focusing on enabling technologies for IR 4.0, such as advanced robotics, digital factory, big data analytics, IoT, and machine learning, and circular economy relevant sectors, such as energy (solar photovoltaics, bioenergy, and system solutions), food/agriculture, and materials. Another activity is conducting training: Strategic Communication Training for young researchers to enhance visibility and impact, build confidence, acquire presentation skills, and develop a global perspective; and Skills and Mindset Training on the life cycle and critical thinking, media communication skills, and entrepreneurship; and global mindset. STEAM Platform also engages in building strategic partnerships with global organizations (including the Asian Development Bank [ADB], World Bank, and United Nations) to create impact and further enhance motivation and goals for the youth; piloting a general education module GEN352 to scale the STEAM Platform program to undergraduate students within KMUTT; and internships to promote learning by doing. Details of GEN352 can be found in the textbook "Introduction to Circular Economy"

\footnotetext{
${ }^{1}$ The STEAM Platform's progress is being live-updated at its website www.steamplatform.org, the Facebook-STEAM Platform, and YouTube Channel STEAM KMUTT.
} 
published by Springer Nature in October 2020, edited by Lerwen LIU \& Seeram RAMAKRISHNA.

The following two case studies elaborate on these practices:

\section{Example 1: Technology Innovation Contests}

The STEAM Platform was launched by competing in the international contest of InnovAction (iCAN) 2018 held in Hong Kong, China. iCAN started in 2007 at Peking University initially with the goal of promoting students' confidence and capabilities in developing products based on microelectromechanical system (MEMS) technology. It has become one of the world's leading technology innovation competitions for students, hosted by academic institutions in Asia, Europe, and North America.

iCAN 2018 was hosted by the Hong Kong University of Science and Technology (HKUST). The STEAM team first carried out a university-wide campaign to identify and select competitive innovations for competing in iCAN 2018. More than 30 innovations were submitted by students, 5 of which were selected for intensive training after two rounds of pitching with mentorships by experienced international academic and industry mentors. The intensive training involved forming a team mixed with technical and design students as well as their advisors with personalized training by STEAM Founding Director Dr. Lerwen Liu, Senior Advisor Prof. Supapan Seraphin, and Communication and Intellectual Property (IP) Specialist Ms. Eliza Stefaniw from KMUTT for 3 weeks. Five teams were intensively trained on strategic communication (value-chain positioning and real-world relevance, English speaking and writing, and infographic representation), business models, and effective pitching techniques. KMUTT's performance at iCAN 2018 transformed the perception of Thailand in the arena of technology and innovation. The founding director of iCAN Prof. Alice Zhang from Peking University was particularly impressed and invited the STEAM Platform to be an iCAN partner in the Association of Southeast Asian Nations (ASEAN). ${ }^{2}$

The impact of the STEAM Platform on the four teams of undergraduate students (total of 12) who participated is summarized as (i) significantly enhanced selfconfidence; (ii) development of a systematic and structured thinking for communicating deep scientific research; (iii) strengthening motivation for research, innovation, and entrepreneurship by developing the ability to link science to real-world issues relatable to the layman; (iv) obtaining a global perspective and positioning for knowledge and research topics; (v) receiving industry feedback and acknowledgment of their innovation and further strengthening confidence and motivation; and (vi) enriching cultural experience through interacting with peers from other countries.

\footnotetext{
${ }^{2}$ The following is the list of final projects selected and presented at iCAN 2018: (i) innovative pressurizer for engineered cartilage (https://www.youtube.com/watch?v=4HEtA6L-FO0); (ii) Agoribot (https://www.youtube.com/watch? $\mathrm{v}=\mathrm{kc} 8 \mathrm{vlOF} \_\mathrm{vuA} \& \mathrm{t}=137 \mathrm{~s}$ ); (iii) environmentally friendly and machinable lead-free brass (https://www.youtube.com/watch?v=c9KZk7UE9Z4\&t=16s); and (iv) sustainable replacement of antibiotics and preservatives (https://www.youtube.com/watch?v=NqI PfFuOEkA\&t=19s). Posters of the showcase are available at the STEAM Platform website, and their performance videos are in the links given.
} 
One of the STEAM-trained teams (Pacharavajee Duangkaew and Neeranuch Rukying) developed bio-active peptides (with innovative processes resulting in improved functionality and lower cost) during their undergraduate final-year project under the supervision of Dr. Nujarin Jangruja (an assistant professor in the Department of Microbiology). After receiving intensive training on the STEAM Platform, the team, together with their advisor, won first prize in a start-up competition organized by the National Innovation Agency of Thailand on February 2, 2019, Thailand Inventors' Day. They also received first prizes in innovation competitions in Singapore (2018) and Malaysia (2019).

\section{Example 2: Mentoring and Training}

A final-year master's degree student, Mr. Podsawat Worakuldumrongdej (nicknamed Arm), was sent to us for mentoring by his thesis advisor Dr. Thavida Maneewarn (one of the top robotics researchers in Thailand) at the end of April 2019. Under the technical supervision of Dr. Maneewarn, Arm developed a drone with an innovative shooter that is able to perform precision rice seed sowing (with a few centimeters precision), which will transform rice farming and improve life on the farms, especially in Asian countries. He was also involved in producing solar farm-cleaning robots and other autonomous vehicles that are transforming manufacturing in Thailand. We trained Arm on (i) strategic communication for his innovations and products; (ii) zooming out of his innovative shooter, justifying the necessity and relevance of seed sowing on Asian rice farms; (iii) structuring his presentation and speaking/writing in English; (iv) entrepreneurship practices; (v) providing more data and demonstrations on real-field experiments; (vi) designing a business model for ANT Robotics as well as his drone, such as solar farm-cleaning robotics; (vi) business development and management; (vii) confidence building through presentation skills training; and (viii) providing a global platform for him to communicate and receive feedback from experts in agriculture and business from ADB, Japan, and Thailand.

We brought Arm together with other STEAM team members to showcase his solar farm-cleaning robot and drone at the Asia Clean Energy Forum 2019 during June 17-19. Our intensive 6-week training for Arm enabled him to articulate his innovative technology/product/solution, which has attracted interest from ADB's Private Sector Operations Department and Rural Development and Food Security (Agriculture) thematic group. The outcome of our training and mentoring of Arm has resulted in his having the confidence to set up ANT Robotics and become the chief executive officer. Arm was invited to exhibit at the ADB Rural Development and Food Security Forum from October 28 to 30, 2019 and is expected to be funded to conduct field experiments at the International Rice Research Institute in the Philippines in March 2020. See Figure 36.2. 


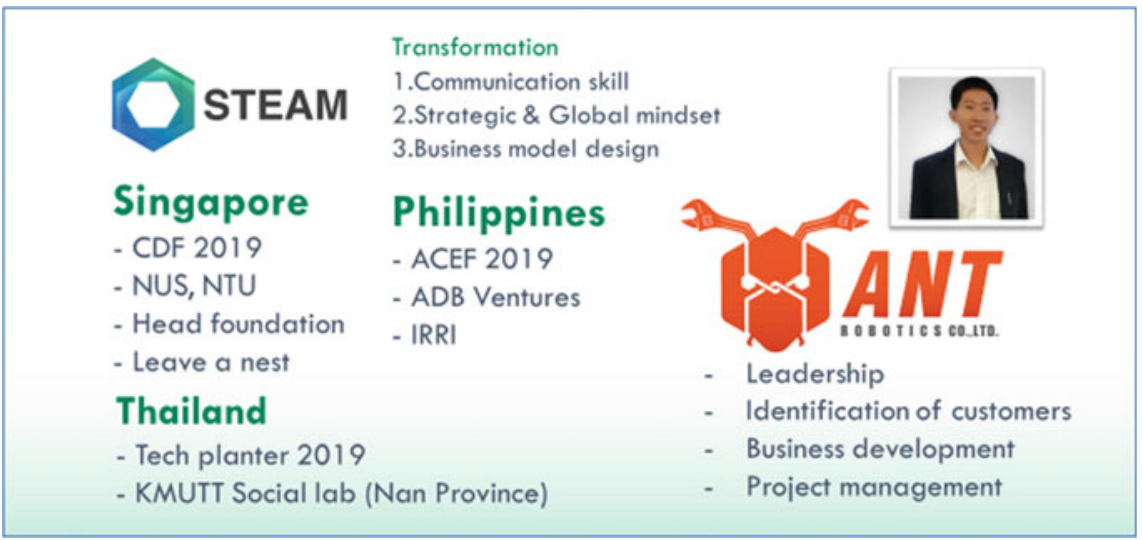

Figure 36.2 Summary of STEAM platform's impact on Arm

\section{Moving Forward}

Within a year, the STEAM Platform has influenced more than 10,000 people worldwide digitally, and over 3,000 physically through events organized and participated in as well as training workshops. It has provided personalized training for more than 300 students and researchers. It has connected with over 100 companies globally and showcased over 50 innovations from KMUTT at global forums. See Figure 36.3.

The STEAM Platform has positioned KMUTT as a representative of Thailand being a regional/global leader in the areas of IR 4.0 and Circular Economy in research,

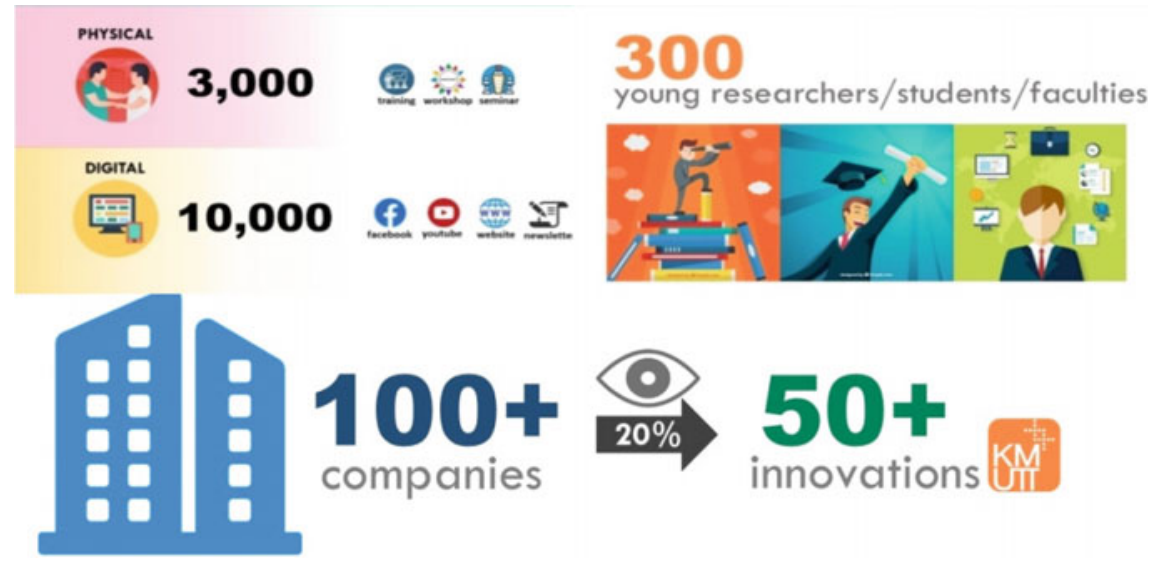

Figure 36.3 Summary of STEAM platform's impact during May 2018 to June 2019 
innovation, education, and entrepreneurship. And KMUTT youth have been transformed to become confident, motivated, more innovative, and entrepreneurial with a global mindset.

We have established partnerships with ADB in the areas of education, rural development, food/agriculture, energy, healthcare, as well as ADB Investments and ADB Ventures; German Corporation for International Cooperation (Deutsche Gesellschaft für Internationale Zusammenarbeit (or GIZ) in the fields of energy, food/agriculture, and circular economy; United Nations Development Programme (UNDP) Co-lab and United Nations Environment Programme (UNEP) in IR 4.0 and Circular Economy and youth entrepreneurship and leadership; and Leave a Nest in the areas of youth entrepreneurship, food/agriculture, and robotics/drone and bio/green materials.

\section{Conclusion}

By combining STEM knowledge with life cycle thinking and strategic communication skills, as well as entrepreneurship practices, Asian youth can be better prepared toward SDGs 2030 and a Smart Circular economy transformation. The STEAM Platform in KMUTT is able to demonstrate this by engaging and empowering youth in its various activities.

A full summary of STEAM Platform activities during 2018-2019 is available on STEAM Platform website (www.steamplatform.org). Currently, KMUTT has funded STEAM Platform during May 2018 to September 2020. We seek partnerships to scale up this platform to empower more youth in developing countries to transform global economic and social dynamics for a sustainable future.

Link to presentation material: https://events.development.asia/materials/201 90927/asian-youth-driven-leadership-platform-towards-smart-ce-transformation. 
The views expressed in this Chapter are those of the authors and do not necessarily reflect the views and policies of the Asian Development Bank (ADB) or its Board of Governors or the governments they represent.

ADB does not guarantee the accuracy of the data included in this Chapter and accepts no responsibility for any consequence of their use. The mention of specific companies or products of manufacturers does not imply that they are endorsed or recommended by ADB in preference to others of a similar nature that are not mentioned.

By making any designation of or reference to a particular territory or geographic area, or by using the term "country" in this Chapter, ADB does not intend to make any judgments as to the legal or other status of any territory or area.

This work is available under the Creative Commons Attribution 3.0 IGO license (CC BY 3.0 IGO) https://creativecommons.org/licenses/by/3.0/igo/. By using the content of this Chapter, you agree to be bound by the terms of this license. For attribution, translations, adaptations, and permissions, please read the provisions and terms of use at https://www.adb.org/terms-use\#openac cess.

This CC license does not apply to non-ADB copyright materials in this Chapter. If the material is attributed to another source, please contact the copyright owner or publisher of that source for permission to reproduce it. ADB cannot be held liable for any claims that arise as a result of your use of the material.

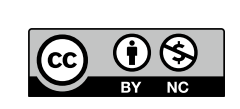

